\title{
Effect of Heat Treatment on the Microstructure, Phase Distribution, and Mechanical Properties of AlCoCuFeMnNi High Entropy Alloy
}

\author{
Gulhan Cakmak \\ Metallurgical and Materials Engineering, Muğla Sitki Kocman University, 48100 Muğla, Turkey \\ Correspondence should be addressed to Gulhan Cakmak; glhnckmk@gmail.com
}

Received 16 May 2017; Accepted 13 July 2017; Published 27 August 2017

Academic Editor: Patrice Berthod

Copyright (c) 2017 Gulhan Cakmak. This is an open access article distributed under the Creative Commons Attribution License, which permits unrestricted use, distribution, and reproduction in any medium, provided the original work is properly cited.

\begin{abstract}
The present paper reports the synthesis of AlCoCuFeMnNi high entropy alloy (HEA) with arc melting process. The as-cast alloy was heat treated at $900^{\circ} \mathrm{C}$ for 8 hours to investigate the effect of heat treatment on the structure and properties. Microstructural and mechanical properties of the alloy were analyzed together with the detailed phase analysis of the samples. The initially ascast sample was composed of two separate phases with BCC and FCC structures having lattice parameters of $2.901 \AA$ and $3.651 \AA$, respectively. The heat-treated alloy displays microsized rod-shaped precipitates both in the matrix and within the second phase. Rietveld refinement has shown that the structure was having three phases with lattice parameters of $2.901 \AA$ (BCC), $3.605 \AA$ (FCC1), and 3.667 $\AA$ (FCC2). The resulting phases and distribution of phases were also confirmed with the TEM methods. The alloys were characterized mechanically with the compression and hardness tests. The yield strength, compressive strength, and Vickers hardness of the as-cast alloy are $1317 \pm 34 \mathrm{MPa}, 1833 \pm 45 \mathrm{MPa}$, and $448 \pm 25 \mathrm{Hv}$, respectively. Heat treatment decreases the hardness values to $419 \pm 26 \mathrm{Hv}$. The maximum compressive stress of the alloy increased to $2123+41 \mathrm{MPa}$ while yield strength decreased to $1095 \pm$ 45 with the treatment.
\end{abstract}

\section{Introduction}

Traditional alloy design approach is based on mixing of one or two primary elements with known properties and minor elements are added in order to improve their properties. According to conventional strategy for developing new alloy systems, multiprincipal elements can lead to the formation of intermetallic compounds and complex microstructures. Yeh et al. [1] and Cantor [2] have broken this thinking pattern with the development of high entropy alloys (HEA). High entropy alloys are the systems with usually more than five principle elements at levels of 5-35 at \% [3-5]. Due to high configurational entropy of these systems, FCC and BCC solid solutions were generally formed rather than intermetallics and complex phases [6-8]. It has been shown that some alloy systems designed with HEA approach show excellent mechanical [8-10] and high-temperature properties [6] and wear [11] and high-temperature softening resistance [12] and so forth and they are suitable for many applications. In many cases the best balance of properties may be achieved for a multiprincipal element alloy consisting of more than one solid solution phase $[8,13]$.

Within the high entropy alloy systems, $\mathrm{AlCoCrFeNi}$ alloy is the one which has extensively been studied [14, 15]. It is well established that the properties of the alloy system depend on the composition. In the current study, we modified this alloy system by replacing $\mathrm{Cr}$ with $\mathrm{Cu}$ and Mn was added as new alloying element. The system was synthesized with arc melting method and characterized with respect to crystal structure, phase stability, microstructure, and mechanical properties. The sample was heat treated at $900^{\circ} \mathrm{C}$ for 8 hours to see high-temperature properties. The resultant microstructures and phases were analyzed before and after heat treatment with the method of X-ray diffraction, scanning electron microscopy, transmission electron microscopy, compression test, and microhardness test. 


\section{Experimental Method}

Equiatomic amount of high purity $\mathrm{Al}$ (99.9\%), Co (99.9\%), $\mathrm{Cu}$ (99.9\%), Fe (99.9\%), Ni (99.9\%), and Mn (99.9\%) was melted in an arc furnace under argon atmosphere. Approximately batches of 3 grams were melted in a water-cooled copper mold. The ingot was remelted three times in order to increase homogeneity. The specimen was evaluated at as-cast condition and heat treated at $900^{\circ} \mathrm{C}$ in an argon atmosphere for 8 hours and furnace cooled.

The phases are characterized with X-ray diffraction method using a Bruker D8 ADVANCE X-ray diffractometer (XRD) with copper target operated at $40 \mathrm{kv} 30 \mathrm{~mA}$. The lattice parameters and crystal structures as well as volume fractions were obtained from the Rietveld refinement of X-ray data with MAUD program [16]. Compositional and microstructural analysis were carried out using FEI Nova NanoSEM 430 equipped with EDS detector.

Thin-foil specimens were prepared by mechanical thinning followed by ion milling and were observed under a transmission electron microscope (200 kV TEM, JEM-2100F, JEOL, Tokyo, Japan).

Mechanical properties were evaluated by uniaxial compression tests on samples with $3 \mathrm{~mm}$ diameter and $4.5 \mathrm{~mm}$ length by using an Instron 5582 testing system with a strain rate of $10^{-3} \mathrm{~s}^{-1}$. Three compression tests were performed to obtain average value. The hardness values were measured using $4.903 \mathrm{~N}$ load for $10 \mathrm{sec}$. The reported hardness value was an average of at least 10 measurements.

\section{Results and Discussion}

3.1. Phase Analysis. Figure 1(a) shows the X-ray diffraction (XRD) pattern of the as-cast sample with the aforementioned composition. Detailed Rietveld refinement of the XRD data shows that as-cast sample is composed of two solid solution phases with body centered cubic (BCC) and face centered cubic (FCC) crystal structure. The lattice parameters of the BCC solid solution and FCC solid solutions are found to be $2.901 \AA$ and $3.651 \AA$, respectively. The relative fractions of these two phases are $65.66 \%$ (BCC) and $34.34 \%$ (FCC).

The alloy was heat treated at $900^{\circ} \mathrm{C}$ for 8 hours. After heat treatment, a second FCC phase with similar lattice parameter appeared on XRD data with BCC phase seen in as-cast sample remaining in the structure (Figure 1(b)). The lattice parameters of the two FCC phases are calculated to be $3.667 \AA$ and $3.605 \AA$, while the lattice constant of BCC phase is determined to be $2.893 \AA$. The relative fractions of these phases are found to be $26.82 \%, 19.53 \%$, and 53.65 , respectively. The corresponding phases, their lattice parameters, and volume fractions of these two conditions have been listed in Table 1. Rietveld refined X-ray diffractogram of the heattreated sample is given in Figure 2. It should be noted here that we see the transformation of some fraction of BCC and FCC phases to another FCC phase which we will call FCC-2 from now on.

3.2. Microstructure and Chemical Composition Analysis. Figure 3(a) presents the backscattered electron image of the ascast alloy. It is seen from the image that the microstructure

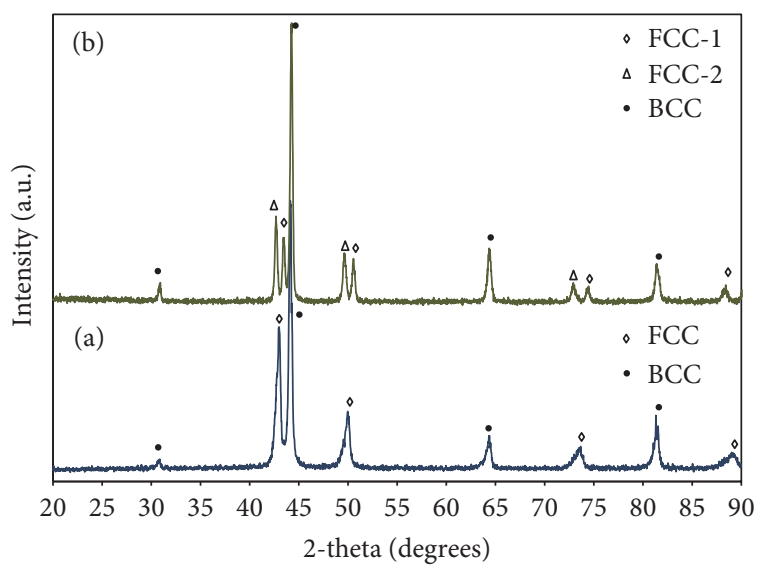

FIgURE 1: X-ray diffractograms for AlCoCuFeMnNi (a) before heat treatment and (b) after heat treatment.

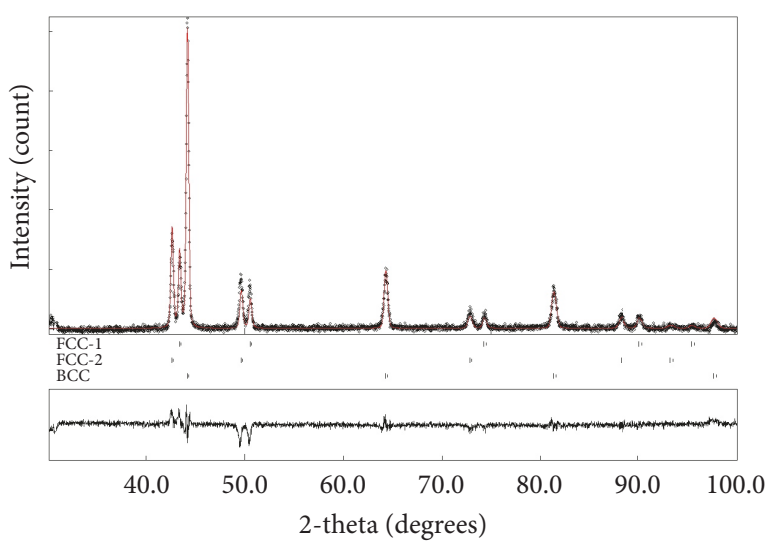

FIGURE 2: Rietveld refined X-ray diffractogram of heat-treated sample.

contains a main phase exhibiting relatively darker contrast and another phase with brighter contrast, which is consistent with XRD results. The overall atomic composition which is obtained from energy dispersive spectroscopy (EDS) analysis of the as-cast sample and point analysis of the darker and brighter phases is given in Table 2 . It can be seen that the darker phase is enriched with $\mathrm{Al}$ while brighter regions are enriched with $\mathrm{Fe}$ and $\mathrm{Cu}$.

Heat treatment of the sample leads to the formation of more complex microstructure, which is supported by X-ray diffraction analysis, Figure 3(b). A closer look to the microstructure reveals that rod-shaped precipitates are visible within both darker and brighter areas (refer to Figure 3(c)).

As it can be seen from the SEM image there seems to be four regions. These regions can be named as (1) the dark matrix phase (MP) and (2) bright precipitates within matrix phase (PM) and (3) bright secondary phase (SP) and (4) dark precipitates within secondary phase (PS). To understand the nature of these regions, point elemental analyses are applied to each region and these values are also included in Table 2. Although the resulting quantitative values have 
TABLE 1: Rietveld Refinement results of the as-cast and heat-treated sample.

\begin{tabular}{lccc}
\hline & Phase & Lattice parameter $(\AA)$ & Phase fractions $(\%)$ \\
\hline \multirow{2}{*}{ As-cast } & BCC & 2.901 & 65.66 \\
& FCC & 3.651 & 34.34 \\
\hline \multirow{3}{*}{ Heat-treated } & BCC & 2.893 & 53.64 \\
& FCC-1 & 3.667 & 26.83 \\
& FCC-2 & 3.605 & 19.53 \\
\hline
\end{tabular}

TABLE 2: Chemical composition of the as-cast and heat-treated alloys.

\begin{tabular}{|c|c|c|c|c|c|c|}
\hline & $\mathrm{Al}$ & $\mathrm{Mn}$ & $\mathrm{Fe}$ & Co & $\mathrm{Ni}$ & $\mathrm{Cu}$ \\
\hline \multicolumn{7}{|l|}{ As-cast } \\
\hline Bright & 12,04 & 17,28 & 20,32 & 16,40 & 13,94 & 20,04 \\
\hline Dark & 21,49 & 15,36 & 15,12 & 16,07 & 17,35 & 14,61 \\
\hline \multicolumn{7}{|c|}{ Heat-treated } \\
\hline$S P$ & 9,92 & 15,67 & 14,87 & 12,51 & 12,76 & 34,28 \\
\hline$P S$ & 19,12 & 15,53 & 17,12 & 16,00 & 16,41 & 15,82 \\
\hline$P M$ & 16,25 & 15,41 & 17,12 & 14,96 & 14,19 & 22,08 \\
\hline$M P$ & 21,78 & 15,28 & 17,07 & 18,03 & 18,25 & 9,60 \\
\hline Overall & 17,92 & 16,70 & 16,19 & 15,87 & 16,27 & 17,07 \\
\hline
\end{tabular}

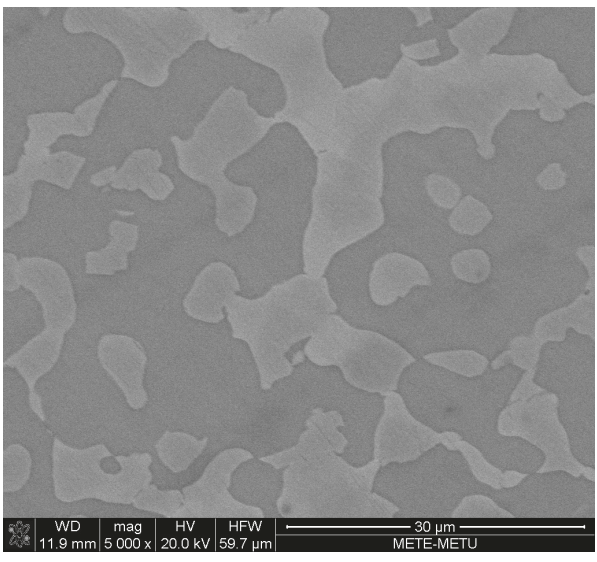

(a)

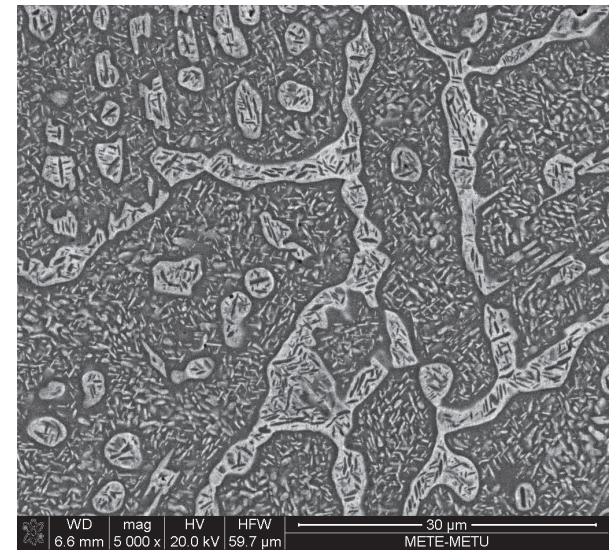

(b)

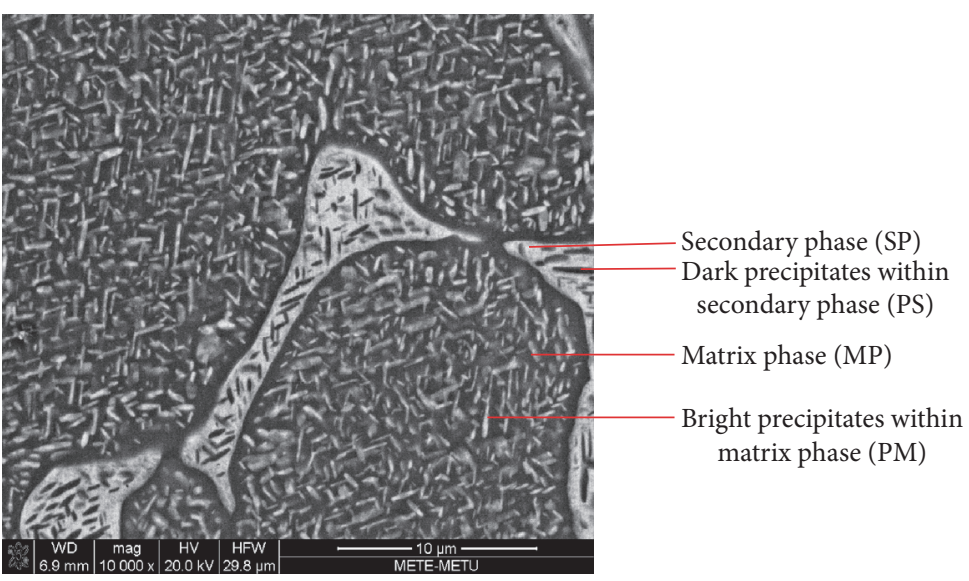

(c)

FIGURE 3: Backscattered SEM images of the (a) as-cast and (b) heat-treated sample. (c) A closer look to the heat-treated sample. 

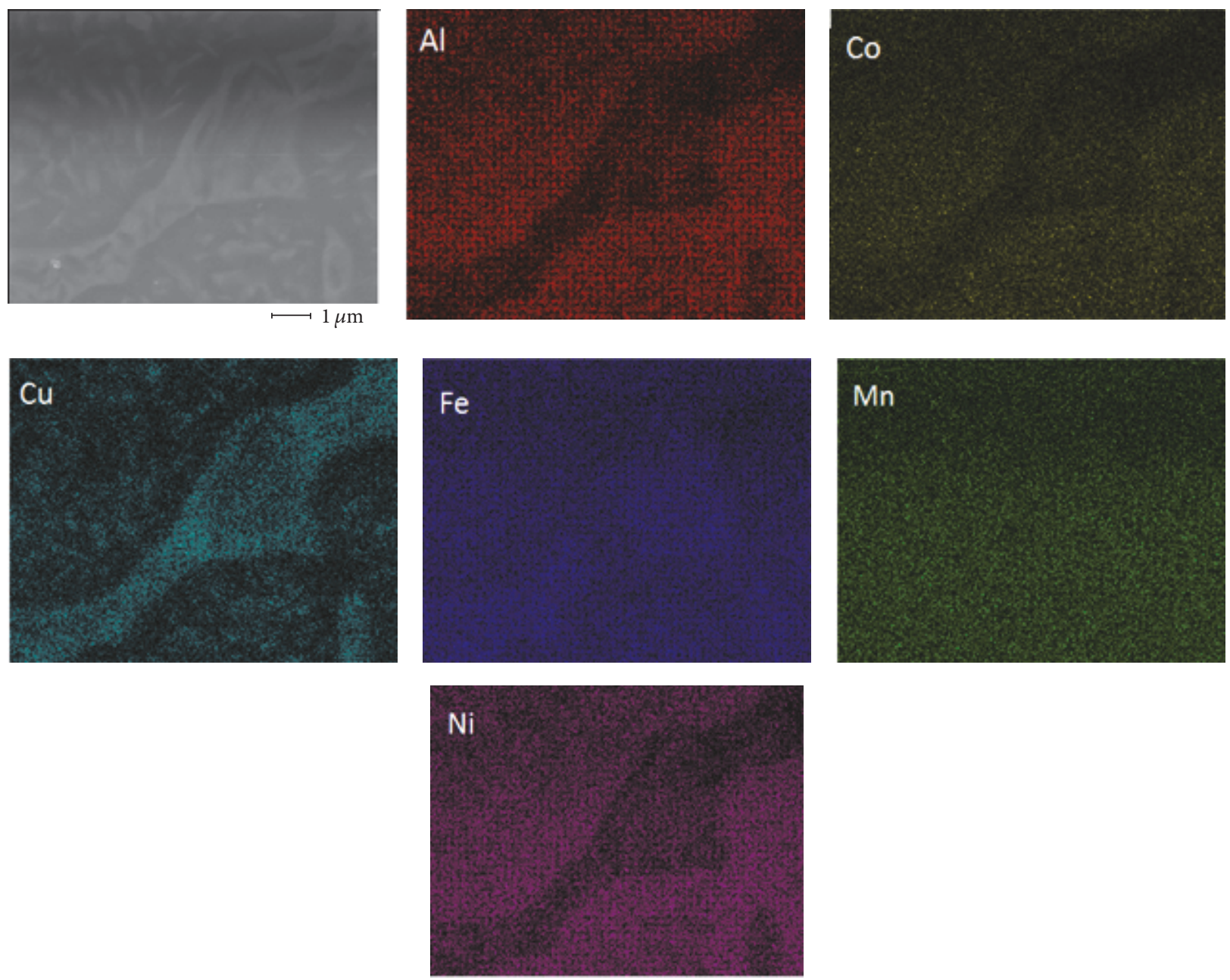

FIGURE 4: Elemental mapping of the heat-treated high entropy alloy.

restricted accuracy due to small sizes of phases, the values can give rough information related to compositional distribution among four regions. The values in Table 2 show that composition of the matrix phase (MP) is found to be rich in Al while bright secondary phase (SP) is rich in $\mathrm{Cu}$.

In order to verify the compositional variation within the microstructure, the elemental mapping was carried out and the colored maps are given in Figure 4. It is seen that the matrix phase has more $\mathrm{Al}, \mathrm{Co}$, and $\mathrm{Ni}$ than the secondary phase which is rich in $\mathrm{Cu}$. The needle-like precipitates within the matrix are enriched with $\mathrm{Cu}$.

\subsection{Transmission Electron Microscopy Analysis. The obtained} phase distribution has further been verified with TEM analysis. The similar microstructure obtained from SEM analysis is observed in TEM. Bright field TEM image for the heat-treated sample is shown in Figure 5(a). The upper inset (b) shows diffraction pattern from matrix region (MP) and is found to have BCC structure with [102] BCC zone axis. Similarly lower inset (c) has been obtained from the precipitate in matrix (PM) and has FCC structure from [031] FCC zone axis. Crystal structure of the second phase is also determined using selected area diffraction pattern. The diffraction patterns are obtained from the bright field image shown in Figure 5(d) and the patterns are indexed for the second-phase particle (upper inset, (e)) and for the precipitate in second phase (lower inset, (f)). The structures have been found to be FCC from [211] FCC zone axis and BCC from [311] BCC zone axis, respectively. To summarize TEM images and diffraction patterns, it can be said that the matrix phase (MP) and dark precipitates within secondary phase (PS) are found to be BCC with the same lattice parameter while secondary phase (SP) and bright precipitates within matrix phase (PM) are found to be FCC phases with two different but close lattice parameters.

3.4. Mechanical Analysis. Figure 6 shows the engineering stress-strain curve of heat treated AlCoCuFeMnNi HEA under compression at room temperature. The yield strength $(\sigma y)$ and compressive strength $(\sigma \max )$ values of AlCoCuFeMnNi HEA are $1095 \pm 45 \mathrm{MPa}$ and $2123 \pm 41 \mathrm{MPa}$, respectively. The values before heat treatment were also shown in Figure 6 and measured to be $1317 \pm 34$ and $1833 \pm$ $45 \mathrm{MPa}$, respectively. Increase in compression strength of the 


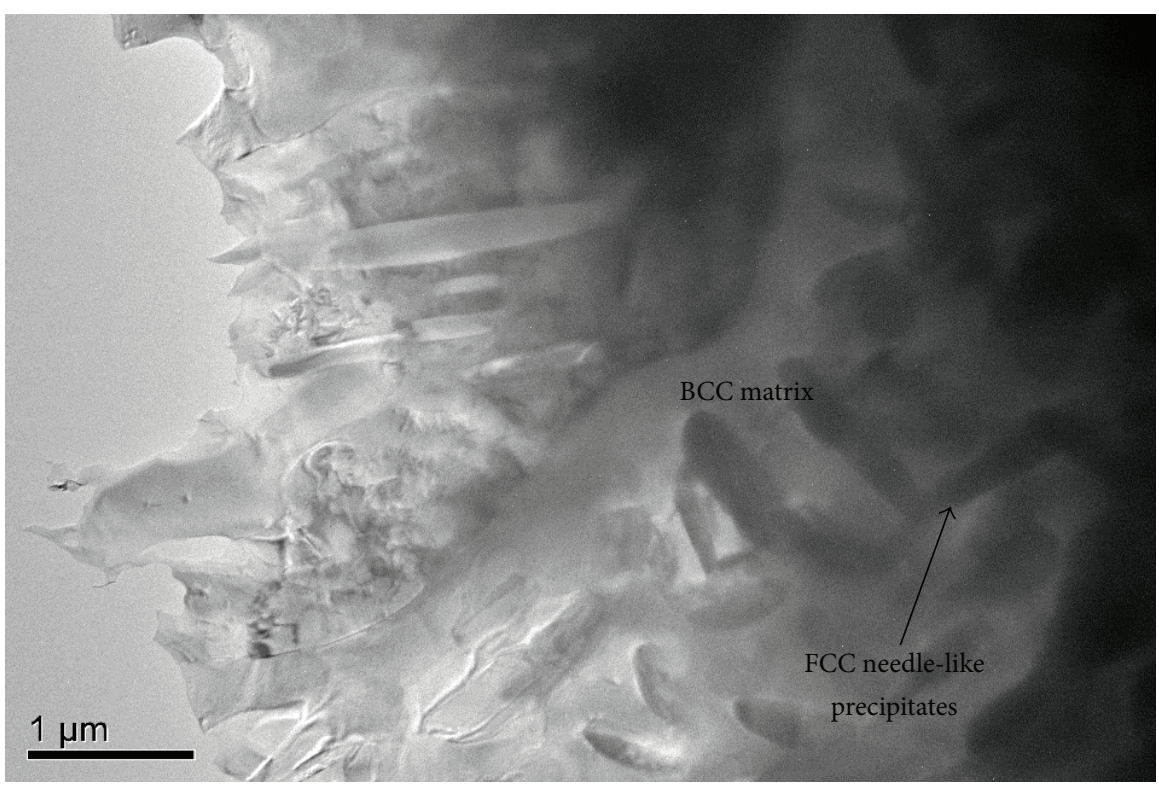

(a)

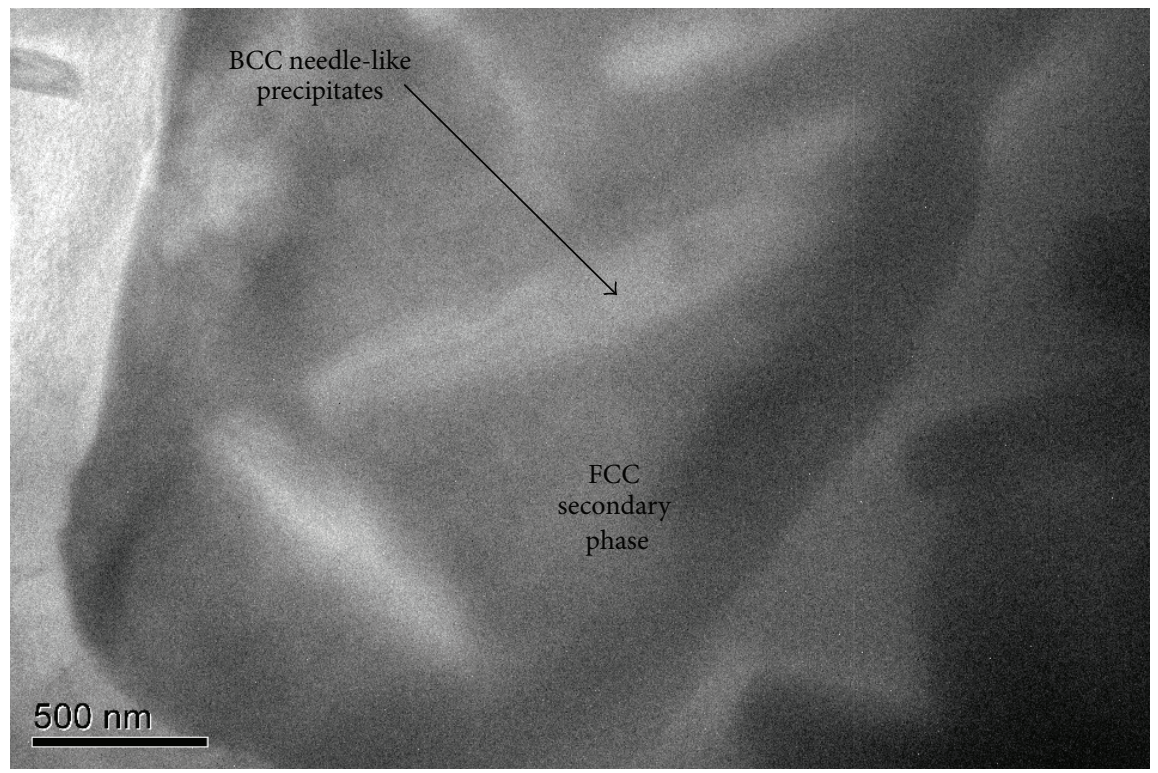

(d)

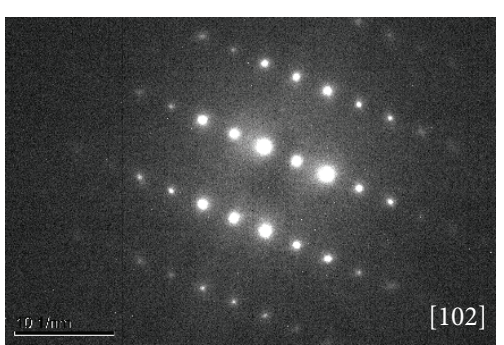

(b)

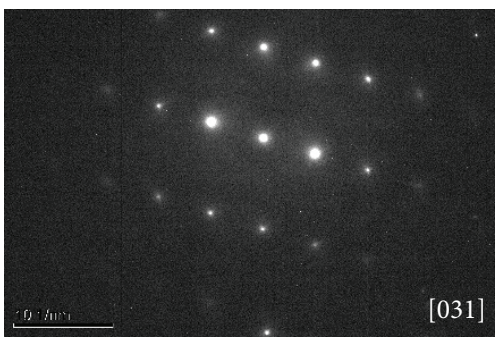

(c)

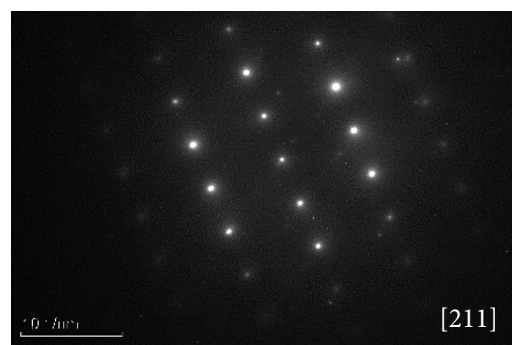

(e)

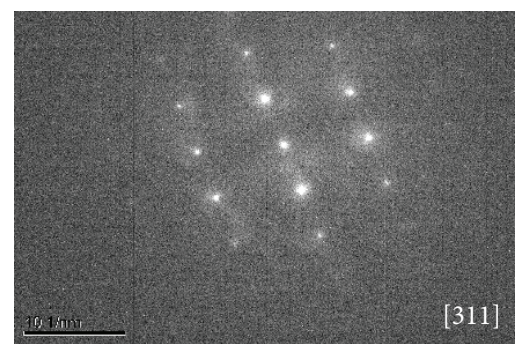

(f)

FIGURE 5: TEM image and corresponding SAED patterns of bulk AlCoCuFeMnNi HEA after heat treatment. (a) Bright field image showing the primary and secondary phases. (b) SAED pattern of the matrix from [102 $]_{\mathrm{BCC}}$ zone axis; (c) SAED pattern of FCC needle-like precipitates from $[031]_{\text {FCC }}$ zone axis; (d) bright field image showing the second phase and needle-like precipitates within; (e) SAED pattern of the second phase particle from [211] FCC zone axis; (f) SAED pattern of the needle-like precipitates within secondary phase from [311 $]_{\mathrm{BCC}}$ zone axis.

material can be related to the small sized precipitates within the heat-treated sample [17].

The microhardness value of the AlCoCuFeMnNi alloy was $448 \pm 25 \mathrm{Hv}$ while with heat treatment it was measured to be $419 \pm 26 \mathrm{Hv}$. A decrease was observed in the microhardness values with heat treatment since there is a decrease in the volume fraction of BCC phase, which exhibits higher hardness/strength than that of the FCC phases, consistent with what has been previously reported [17-19].

\section{Conclusion}

In the current study, we investigate the effect of heat treatment on the microstructure and phase distribution and on the mechanical properties of the alloy. We observe that two phase structures which were initially FCC and BCC structure were converted into three phase structures with one BCC and two FCC structures with heat treatment. The SEM micrographs show that the phases of HEA exhibit rod-shaped precipitates 


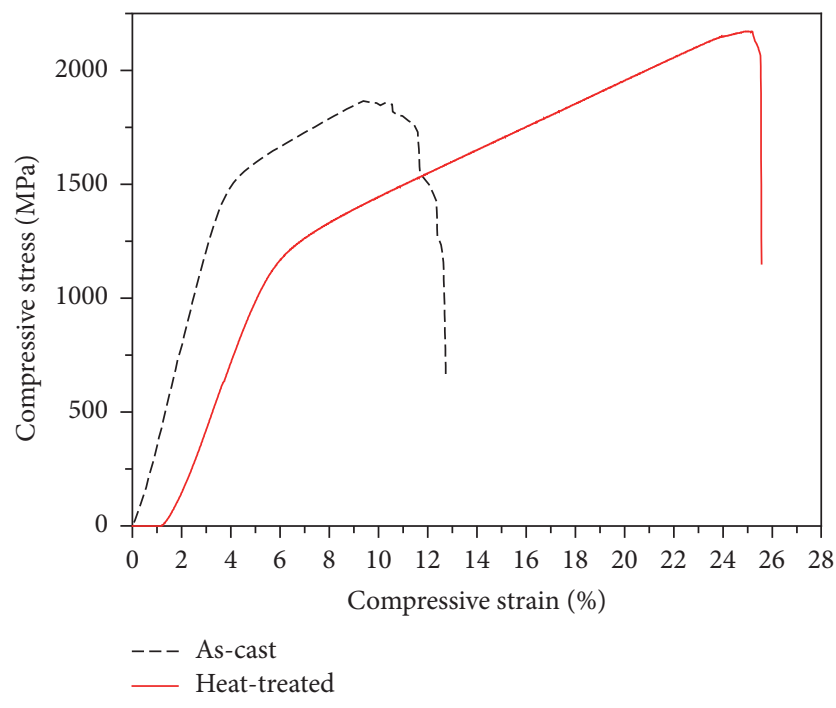

FIGURE 6: Engineering stress-strain curve of bulk AlCoCuFeMnNi HEA under compression.

within both the matrix and second phase. TEM analyses verify that these three phases were distributed as the FCC precipitates (PM) in BCC matrix (MP) and as BCC precipitates (PS) in FCC second phase (SP). These two FCC phases have close lattice parameters as $3.605 \AA$ and $3.667 \AA$. This change in microstructure and phase constitution was accompanied by a corresponding progressive decrease in microhardness with decreasing BCC content, clearly indicating that the BCC microstructure is substantially harder than the FCC microstructure. The corresponding increase on mechanical strength value was thought to be related to small sized precipitates within the structure.

\section{Conflicts of Interest}

The author declares that there are no conflicts of interest regarding the publication of this paper.

\section{References}

[1] J.-W. Yeh, S.-K. Chen, S.-J. Lin et al., "Nanostructured highentropy alloys with multiple principal elements: novel alloy design concepts and outcomes," Advanced Engineering Materials, vol. 6, no. 5, pp. 299-303, 2004.

[2] B. Cantor, "Multicomponent and high entropy alloys," Entropy, vol. 16, no. 9, pp. 4749-4768, 2014.

[3] X. F. Wang, Y. Zhang, Y. Qiao, and G. L. Chen, "Novel microstructure and properties of multicomponent CoCrCuFeNiTix alloys," Intermetallics, vol. 15, no. 3, pp. 357-362, 2007.

[4] J.-W. Yeh, S.-J. Lin, T.-S. Chin et al., "Formation of simple crystal structures in $\mathrm{Cu}-\mathrm{Co}-\mathrm{Ni}-\mathrm{Cr}-\mathrm{Al}-\mathrm{Fe}-\mathrm{Ti}-\mathrm{V}$ alloys with multiprincipal metallic elements," Metallurgical and Materials Transactions A, vol. 35, no. 8, pp. 2533-2536, 2004.

[5] C.-W. Tsai, M.-H. Tsai, J.-W. Yeh, and C.-C. Yang, "Effect of temperature on mechanical properties of $\mathrm{Al}_{0.5} \mathrm{CoCrCuFeNi}$ wrought alloy," Journal of Alloys and Compounds, vol. 490, no. 1-2, pp. 160-165, 2010.

[6] S. Varalakshmi, M. Kamaraj, and B. S. Murty, "Processing and properties of nanocrystalline CuNiCoZnAlTi high entropy alloys by mechanical alloying," Materials Science and Engineering A, vol. 527, no. 4-5, pp. 1027-1030, 2010.

[7] C.-J. Tong, M.-R. Chen, J.-W. Yeh et al., "Mechanical performance of the $\mathrm{Al}_{x} \mathrm{CoCrCuFeNi}$ high-entropy alloy system with multiprincipal elements," Metallurgical and Materials Transactions A, vol. 36, no. 5, pp. 1263-1271, 2005.

[8] Y. J. Zhou, Y. Zhang, Y. L. Wang, and G. L. Chen, "Solid solution alloys of $\mathrm{AlCoCrFeNiTi}_{x}$ with excellent room-temperature mechanical properties," Applied Physics Letters, vol. 90, no. 18, p. $181904,2007$.

[9] W.-R. Wang, W.-L. Wang, S.-C. Wang, Y.-C. Tsai, C.-H. Lai, and J.-W. Yeh, "Effects of $\mathrm{Al}$ addition on the microstructure and mechanical property of $\mathrm{Al}$ xCoCrFeNi high-entropy alloys," Intermetallics, vol. 26, pp. 44-51, 2012.

[10] X. Ye, M. Ma, W. Liu et al., "Synthesis and Characterization of High-Entropy Alloy $\mathrm{Al}_{x} \mathrm{FeCoNiCuCr}$ by Laser Cladding," Advances in Materials Science and Engineering, vol. 2011, Article ID 485942, 7 pages, 2011.

[11] P.-K. Hung, J.-W. Yeh, T.-T. Shun, and S.-K. Chen, "Multiprincipal-element alloys with improved oxidation and wear resistance for thermal spray coating," Advanced Engineering Materials, vol. 6, no. 1-2, pp. 74-78, 2004.

[12] C.-Y. Hsu, C.-C. Juan, W.-R. Wang, T.-S. Sheu, J.-W. Yeh, and S.$\mathrm{K}$. Chen, "On the superior hot hardness and softening resistance of AlCoCrxFeMo0.5Ni high-entropy alloys," Materials Science and Engineering A, vol. 528, no. 10-11, pp. 3581-3588, 2011.

[13] D. B. Miracle, J. D. Miller, O. N. Senkov, C. Woodward, M. D. Uchic, and J. Tiley, "Exploration and development of high entropy alloys for structural applications," Entropy, vol. 16, no. 1, pp. 494-525, 2014.

[14] H.-P. Chou, Y.-S. Chang, S.-K. Chen, and J.-W. Yeh, "Microstructure, thermophysical and electrical properties in $\mathrm{Al}_{x} \mathrm{CoCrFeNi}(0 \leq \mathrm{x} \leq 2)$ high-entropy alloys," Materials Science and Engineering: B, vol. 163, no. 3, pp. 184-189, 2009.

[15] Y. P. Wang, B. S. Li, M. X. Ren, C. Yang, and H. Z. Fu, "Microstructure and compressive properties of $\mathrm{AlCrFeCoNi}$ high entropy alloy," Materials Science and Engineering: A, vol. 491, no. 1-2, pp. 154-158, 2008.

[16] L. Lutterotti, S. Matthies, and H. R. Wenk, Int Union Crystallogr Comm Powder Diffr Newslett 1999, 21, p. 14 MAUD Version 2.072, 2008 http://maud.radiographema.eu/.

[17] T. Borkar, B. Gwalani, D. Choudhuri et al., "A combinatorial assessment of AlxCrCuFeNi2 $(0<\mathrm{x}<1.5)$ complex concentrated alloys: Microstructure, microhardness, and magnetic properties," Acta Materialia, vol. 116, pp. 63-76, 2016.

[18] J.-M. Wua, S.-J. Lin, J.-W. Yeh, S.-K. Chen, Y.-S. Huang, and H.-C. Chen, "Adhesive wear behavior of $\mathrm{Al}_{x} \mathrm{CoCrCuFeNi}$ highentropy alloys as a function of aluminum content," Wear, vol. 261, no. 5-6, pp. 513-519, 2006.

[19] M.-H. Tsai and J.-W. Yeh, "High-entropy alloys: a critical review," Materials Research Letters, vol. 2, no. 3, pp. 107-123, 2014. 

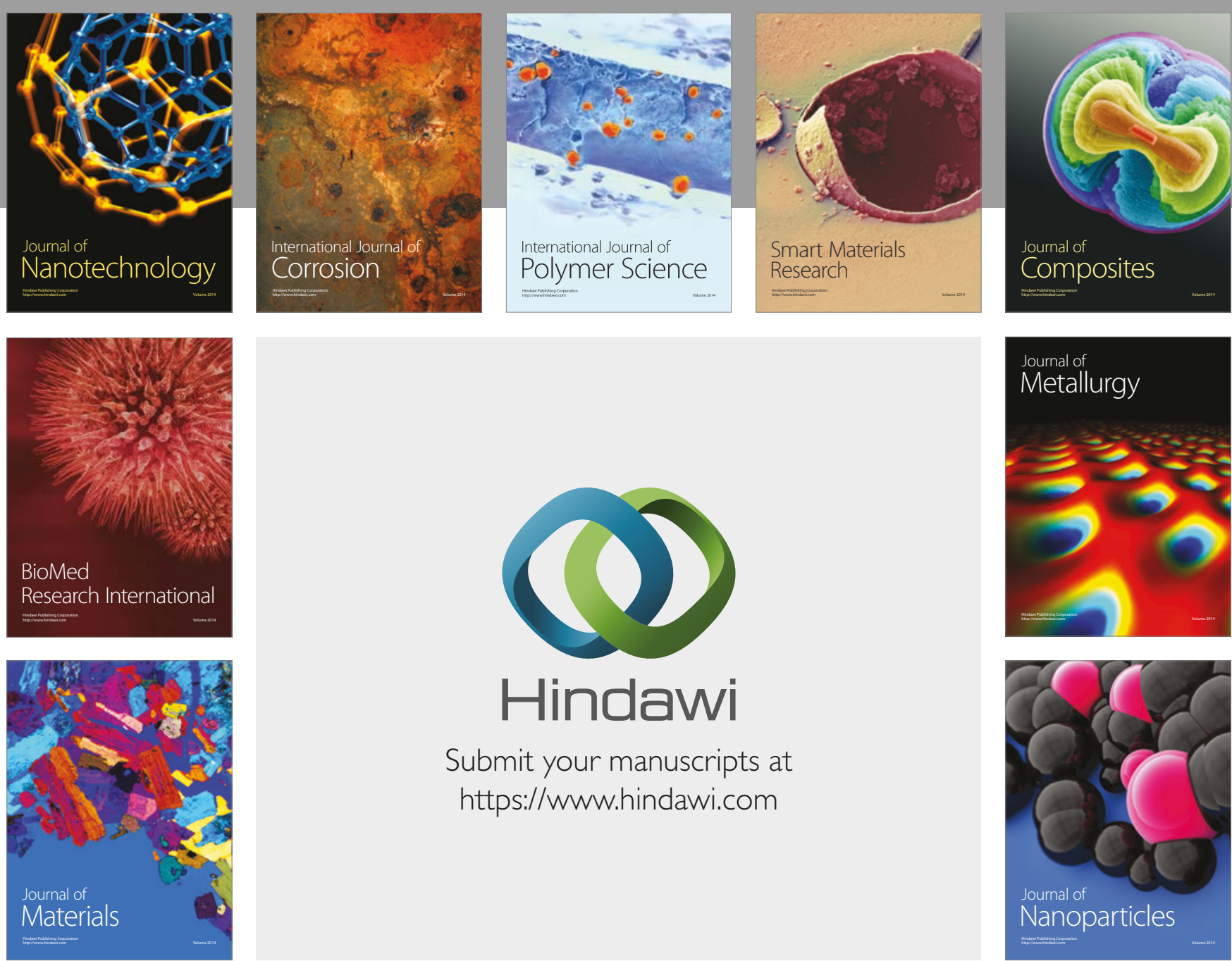

\section{Hindawi}

Submit your manuscripts at

https://www.hindawi.com
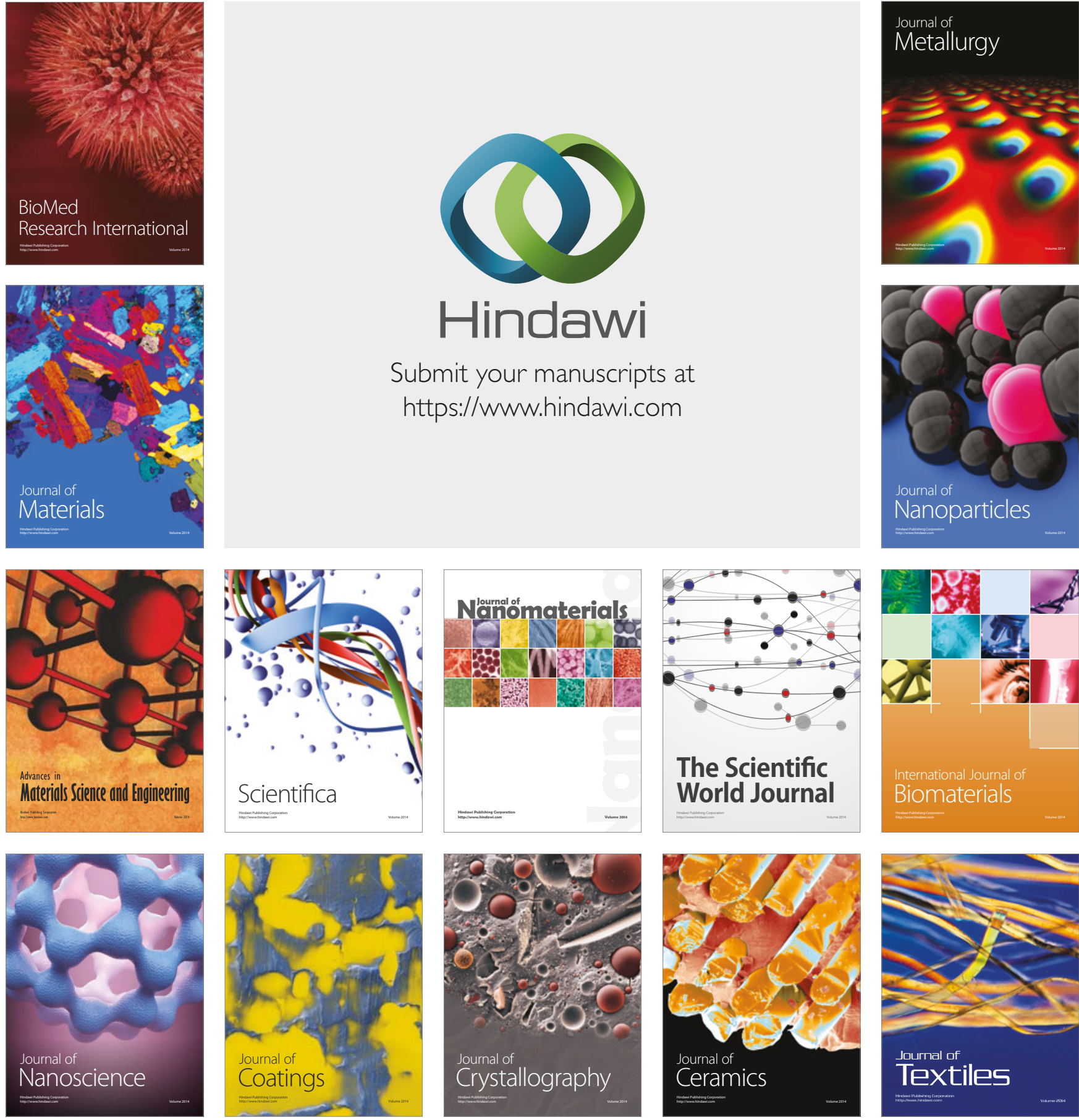

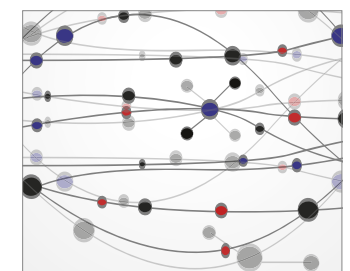

The Scientific World Journal
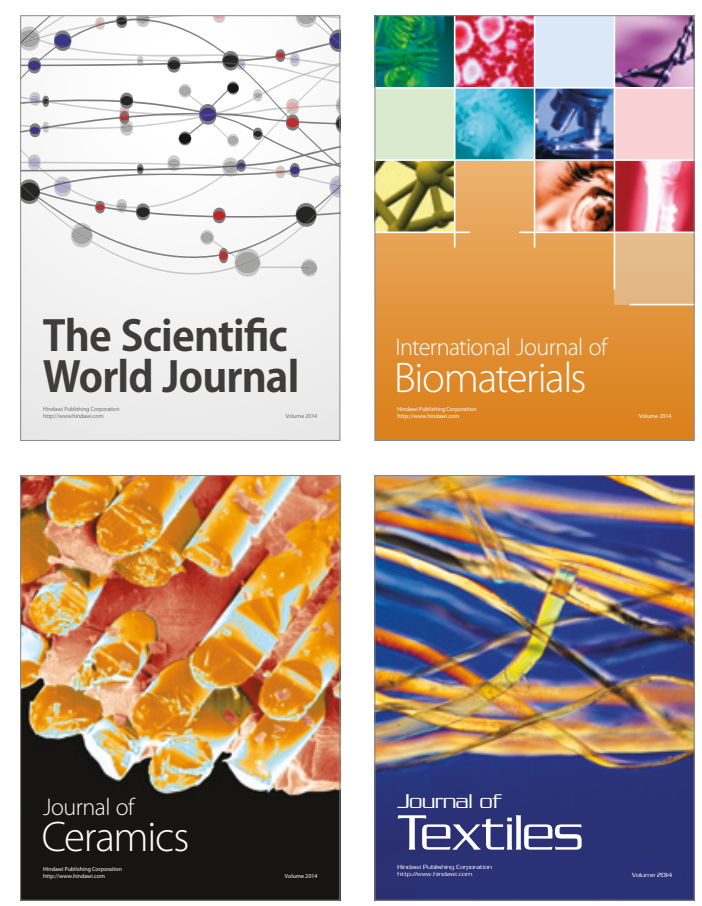